Article

\title{
Understanding the Role of Temperature and Drain Current Stress in InSnZnO TFTs with Various Active Layer Thicknesses
}

\author{
Dapeng Wang $1, * \mathbb{C}$, Mamoru Furuta $2,3, * \mathbb{C}$, Shigekazu Tomai ${ }^{4}$ and Koki Yano ${ }^{4}$ \\ 1 Key Laboratory of Applied Surface and Colloid Chemistry, Ministry of Education; Shaanxi Key Laboratory \\ for Advanced Energy Devices; Shaanxi Engineering Lab for Advanced Energy Technology, School of \\ Materials Science and Engineering, Shaanxi Normal University, Xi'an 710119, China \\ 2 School of Environmental Science and Engineering, Kochi University of Technology, Kami, \\ Kochi 782-8502, Japan \\ 3 Center for Nanotechnology in Research Institute, Kochi University of Technology, Kami, \\ Kochi 782-8502, Japan \\ 4 Advanced Technology Research Laboratories, Idemitsu Kosan Co. Ltd., Sodegaura, Chiba 299-0293, Japan; \\ shigekazu.tomai.6560@idss.co.jp (S.T.); koki.yano@idemitsu.com (K.Y.) \\ * Correspondence: dpwang@snnu.edu.cn (D.W.); furuta.mamoru@kochi-tech.ac.jp (M.F.)
}

Received: 25 February 2020; Accepted: 24 March 2020; Published: 27 March 2020

check for updates

\begin{abstract}
Thin-film transistor (TFT) devices composed of metal oxide semiconductors have attracted tremendous research attention globally in recent years. Owing to their ability to offer mobility, metal oxide semiconductor materials can enable high-performance TFTs for next-generation integrated display devices. Nevertheless, further breakthroughs of metal oxide TFTs are mainly obstructed by their long-term variability, the reason for which is not yet fully understood. Herein, TFTs based on InSnZnO (ITZO) with various thicknesses $\left(T_{\text {ITZO }}\right.$ ) were prepared and their long-term stabilities under test temperatures and drain current stress were investigated. The results indicate that ITZO TFTs exhibit outstanding electrical properties regardless of the $T_{\text {ITZO }}$, including a high saturated mobility of over $35 \mathrm{~cm}^{2} \mathrm{~V}^{-1} \mathrm{~s}^{-1}$ and sharp subthreshold swing. Note that the transfer and output characteristic curves of the device with a thick $T_{\text {ITZO }}$ of $100 \mathrm{~nm}$ express an abnormal current surge when high gate and drain voltages are exerted, which is attributed to the floating body effect, caused when the imposed electric field induces impact ionization near the drain side. More interestingly, these drain current stress results further suggest that the abnormal shift behavior of the electrical properties of the ITZO TFTs with a $T_{\text {ITZO }}$ of greater than $75 \mathrm{~nm}$ is observed to deteriorate gradually with increasing temperature and drain current bias. This study addresses that such a degradation effect should be restrained for the operation of high-mobility devices.
\end{abstract}

Keywords: drain current bias; test temperature; InSnZnO; TFT device; channel layer thickness

\section{Introduction}

Metal oxide semiconductors have recently emerged as extremely sought-after materials for thin-film transistor (TFT) applications [1-6]. Over the past decade, the mobility $(\mu)$ of TFTs employing these semiconductors, such as $\mathrm{InGaZnO}$, has greatly increased, and is comparable to that of polysilicon-based devices [7]. These metal oxide semiconductors also possess promise for various optoelectronic applications, including photodetectors and solar cells [8-11]. Inspired by the achievement of metal oxide films, another category of these materials, called InSnZnO (ITZO), was studied by our group in 2012 [12]. From the perspective of potential applications in flat panel displays 
(FPDs), the ITZO TFTs have been gifted with desirable electrical properties, especially the high $\mu$ of $>30 \mathrm{~cm}^{2} \mathrm{~V}^{-1} \mathrm{~s}^{-1}$, which originates from the $5 \mathrm{~s}$ orbital overlaps of In and Sn atoms [13].

Besides the tremendous developments of metal oxide semiconductors and TFT structures, an intensive understanding of the charge-carrier transport processes is beneficial to further improving the TFT characteristics. In addition, the systematic carrier motion model extending to the internal active layer, which is the core of operating TFT devices, still needs to be studied. Adjusting the metal oxide thickness is an intuitive and effective parameter of the model to investigate the charge transport processes in the bulk of the active layer with [14-16], while leaving the condition of the adjacent interfaces almost unchanged. Apart from the design and fabrication of TFT architectures, the measurement approach is also a crucial step to set up the fundamental physical framework [17]. In addition, in terms of TFT devices, the long-term stabilities are critical to drive TFT-contained integrated circuits in FPDs [18,19]. Moreover, the drain current stress is a common working procedure in current-biased TFTs [20].

In this regard, here the typical TFT device structure is considered to verify the universality of the overall framework. On the basis of the device's architecture, channel layers with different thicknesses $\left(T_{\text {ITZO }}\right)$ are then designed. To evaluate the device's stability, the measurement conditions and working environment are taken into consideration. More importantly, to understand the carrier transport mechanism in the devices, both the channel layer thickness and drain current stress (DCS) should be fully considered.

\section{Experimental}

Figure 1 displays the device architecture and fabrication procedure of ITZO-based TFT, which refers to our previous publication [21]. The chromium gate electrode was prepared on the glass substrate, and the $\mathrm{SiO}_{x}$ gate insulator with a thickness of $150 \mathrm{~nm}$ was formed by plasma-enhanced chemical vapor deposition (PECVD). For the active layers, ITZO films with the thicknesses of 45, 75, and $100 \mathrm{~nm}$ were prepared by DC magnetron sputtering with a mixed gas of $\mathrm{Ar} / \mathrm{O}_{2}=15 / 15 \mathrm{sccm}$ at a deposition pressure of $1 \mathrm{~Pa}$. Then, a $200 \mathrm{~nm}$ thick $\mathrm{SiO}_{x}$ etch-stopper was deposited by PECVD, and indium-tin-oxide source and drain electrodes were formed. Finally, a $\mathrm{SiO}_{\mathrm{x}}$ passivation layer was fabricated by PECVD. After the fabrication of devices with channel widths of $50 \mu \mathrm{m}$ and lengths of $20 \mu \mathrm{m}$, the TFTs were post-treated in a nitrogen atmosphere at $350^{\circ} \mathrm{C}$ for $1 \mathrm{~h}$. All the current-voltage (I-V) results were evaluated by an Agilent 4156C precision semiconductor parameter analyzer in air.

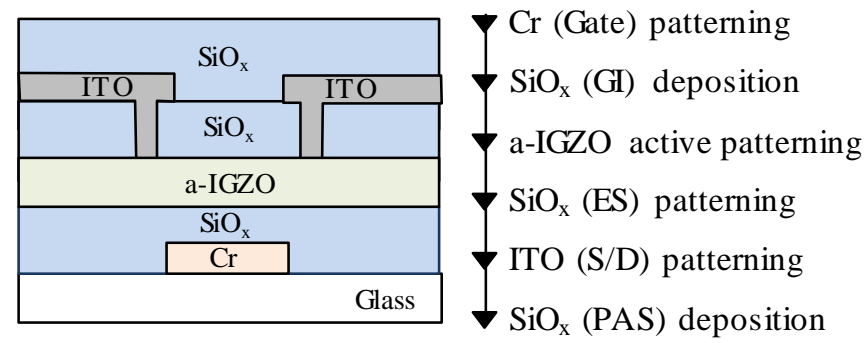

Figure 1. Device architecture and preparation process of the ITZO TFT.

\section{Results and Discussion}

The transfer curves of TFT devices with different $T_{\text {ITZO }}$ were evaluated at a drain voltage $\left(V_{\text {DS }}\right)$ of 0.1 and $20.1 \mathrm{~V}$, as shown in Figure 2. The linear $\left(\mu_{\text {lin }}\right)$ and saturated $\left(\mu_{\text {sat }}\right)$ mobilities were estimated on the basis of previous literature [21]. The turn-on voltage $\left(V_{\mathrm{ON}}\right)$ was extracted from the gate voltage $\left(V_{\mathrm{GS}}\right)$ at a drain current $\left(I_{\mathrm{DS}}\right)$ of $1 \mathrm{nA}$. The hysteresis $\left(\Delta V_{\mathrm{H}}\right)$ was calculated from the $V_{\mathrm{ON}}$ difference value between the forward and reverse scans of the transfer curves. The subthreshold swing (SS) was defined to be $\mathrm{d} V_{\mathrm{GS}} / \mathrm{d} \log _{10}\left(I_{\mathrm{DS}}\right)$. The respective parameters were extracted from the forward sweep, as tabulated in Table 1. 


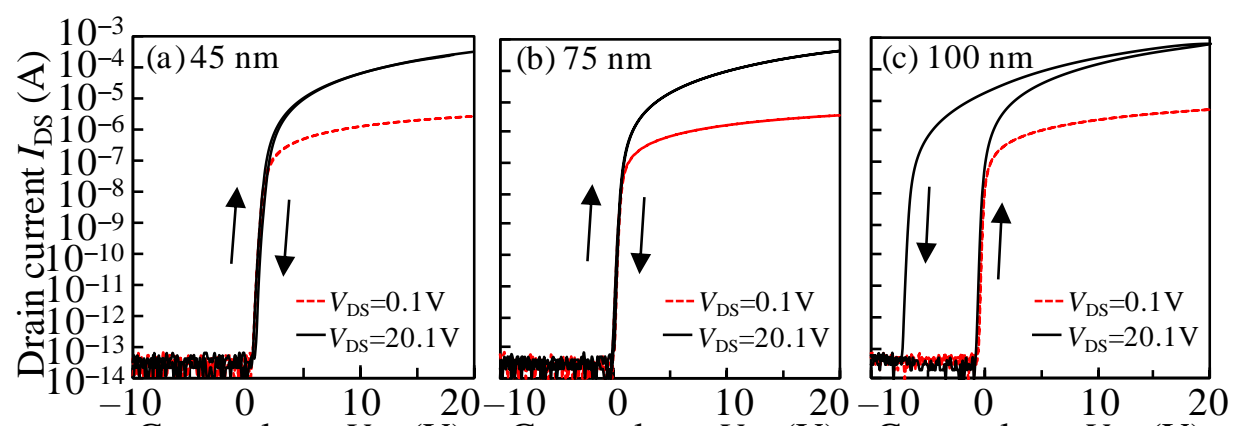

Gate voltage $V_{\mathrm{GS}}(\mathrm{V})$ Gate voltage $V_{\mathrm{GS}}(\mathrm{V})$ Gate voltage $V_{\mathrm{GS}}(\mathrm{V})$

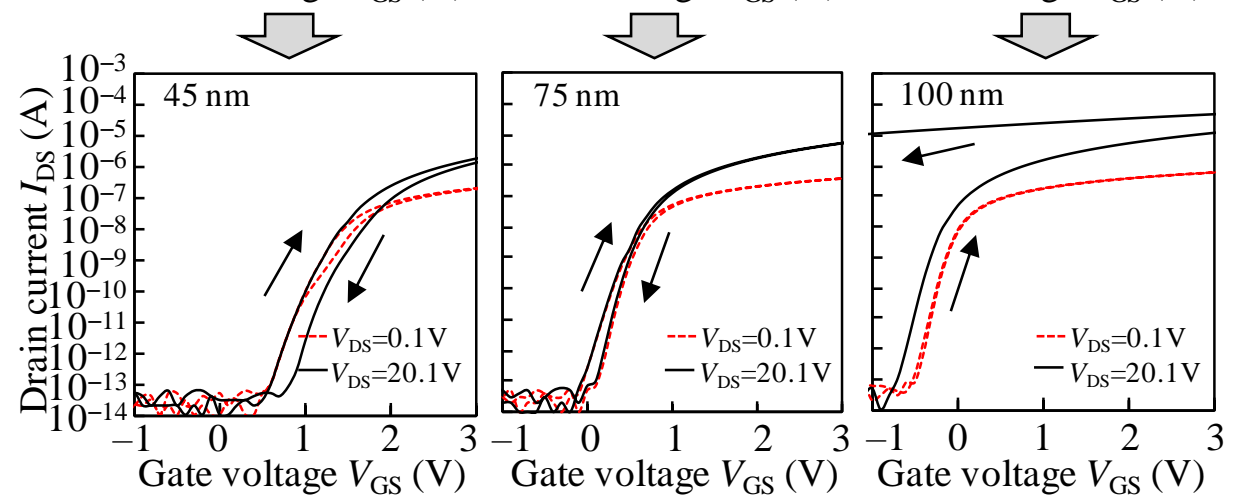

Figure 2. Transfer characteristics of TFT devices with different $T_{\text {ITZO }}$ of (a) 45, (b) 75, and (c) $100 \mathrm{~nm}$ evaluated at a $V_{\mathrm{DS}}$ of 0.1 and $20.1 \mathrm{~V}$.

Table 1. The electrical parameters of a-ITZO TFTs with various $T_{\text {ITZO }}$ extracted from the forward sweep.

\begin{tabular}{cccc}
\hline Thickness $(\mathbf{n m})$ & $\mathbf{4 5}$ & $\mathbf{7 5}$ & $\mathbf{1 0 0}$ \\
\hline$\mu_{\text {lin }}\left(\mathrm{cm}^{2} \cdot \mathrm{V}^{-1} \cdot \mathrm{s}^{-1}\right)$ & 28.76 & 33.27 & 46.36 \\
$\mu_{\text {sat }}\left(\mathrm{cm}^{2} \cdot \mathrm{V}^{-1} \cdot \mathrm{s}^{-1}\right)$ & 35.23 & 46.90 & 130.10 \\
$V_{\text {ON }}$ at $I_{\mathrm{DS}}=1 \mathrm{nA}(\mathrm{V})$ & 1.19 & 0.43 & -0.33 \\
Hysteresis $\Delta V_{\mathrm{H}}(\mathrm{V})$ & 0.22 & 0.07 & -6.38 \\
Subthreshold swing $(\mathrm{mV} /$ dec. $)$ & 169 & 130 & 88 \\
\hline
\end{tabular}

For the device with a $45 \mathrm{~nm} T_{\text {ITZO, }}$ a $\mu_{\text {lin }}$ of $28.76 \mathrm{~cm}^{2} \mathrm{~V}^{-1} \mathrm{~s}^{-1}, \mu_{\text {sat }}$ of $35.23 \mathrm{~cm}^{2} \mathrm{~V}^{-1} \mathrm{~s}^{-1}, V_{\text {ON }}$ of $1.19 \mathrm{~V}, \Delta V_{\mathrm{H}}$ of $0.22 \mathrm{~V}$, and SS of $169 \mathrm{mV} / \mathrm{dec}$. were calculated. The observed results indicate that ITZO-based TFTs exhibit outstanding electrical characteristics which are generally superior to the results of IGZO-based TFT devices [22]. The $\mu_{\text {lin }}$ gradually rose to 33.27 and $46.36 \mathrm{~cm}^{2} \cdot \mathrm{V}^{-1} \cdot \mathrm{s}^{-1}$ when the $T_{\text {ITZO }}$ thickened to 75 and $100 \mathrm{~nm}$, respectively. For the mobility extracted from the saturation region, the $\mu_{\text {sat }}$ significantly increased to $46.90 \mathrm{~cm}^{2} \cdot \mathrm{V}^{-1} \cdot \mathrm{s}^{-1}$ for the $75 \mathrm{~nm} T_{\text {ITZO }}$ device, and sharply soared to $130.10 \mathrm{~cm}^{2} \cdot \mathrm{V}^{-1} \cdot \mathrm{s}^{-1}$ as the $T_{\text {ITZO }}$ further thickened to $100 \mathrm{~nm}$. It was found that the $I_{\mathrm{DS}}$ values significantly increased with the increase in $T_{\text {ITZO }}$. In general, the increase in the $\mu$ and $I_{\mathrm{DS}}$ of the thicker channel TFT was attributed to the increase in carrier concentration and decrease in the density of subgap states, which were based on the percolation conduction and multiple trapping and release model [23,24]. Combined with the transfer curves observed from the $100 \mathrm{~nm} T_{\text {ITZO }}$ TFT measured with a $V_{\mathrm{DS}}$ of $20.1 \mathrm{~V}$ and $V_{\mathrm{GS}}$ of $\sim 20 \mathrm{~V}$, we can conclude that the calculated $\mu_{\text {sat }}$ hardly represents the intrinsic properties of the ITZO material. In the sections of DCS-induced instabilities, for the devices with thicker $T_{\text {ITZO }}$ TFT and measurement modes with a high $V_{\mathrm{DS}}$ and $V_{\mathrm{GS}}$ bias, this conclusion of the sudden increase in the $\mu_{\text {sat }}$ was further confirmed. In addition, the $V_{\mathrm{ON}}$ slightly shifted to 0.43

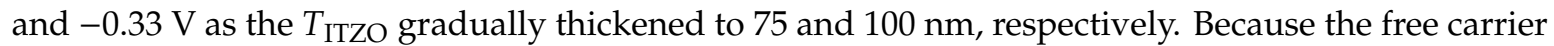
content in the bulk is directly proportional to the thickness of samples [25], the $V_{\mathrm{ON}}$ changed in the negative $V_{\mathrm{GS}}$ direction with the increase in the $T_{\text {ITZO }}$. The negligible clockwise hysteresis was observed for the devices with a $T_{\text {ITZO }}$ of 45 and $75 \mathrm{~nm}$. As the $T_{\text {ITZO was enlarged to } 100 \mathrm{~nm} \text {, an abnormal }}$ 
anticlockwise hysteresis of $-6.38 \mathrm{~V}$ was obtained. In other words, the $V_{\mathrm{GS}}$ was swept forward from -10 to $20 \mathrm{~V}$ with $20.1 \mathrm{~V} V_{\mathrm{DS}}$.

On the basis of the previous publication [26], high- $\mu$ TFTs experiencing drain current stress may induce the floating body effect that impacts ionization, producing electron-hole pairs in the drain side. The generated holes drift to the ITZO/etch-stopper interface due to the longitudinal electric field and flow to the source region due to the transverse electric field. Furthermore, for the TFTs with a thick $T_{\text {ITZO, superfluous holes are trapped in the source area of the back-channel interface, naturally causing }}$ the transfer curve's negative shift. Therefore, in terms of 100-nm-thick ITZO TFTs, a tremendous shift in the negative $V_{\mathrm{GS}}$ direction was observed in the transfer properties, leading to the great hysteresis. Interestingly, the SS values manifest the gradient descent as 130 and $88 \mathrm{mV} / \mathrm{dec}$. as the $T_{\text {ITZO increases }}$ to 75 and $100 \mathrm{~nm}$, respectively. This behavior is due to the fact that the densities of interface traps at

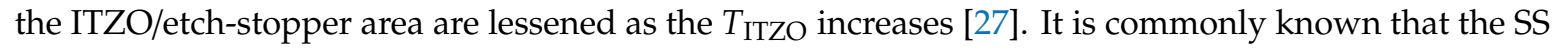
is the direct parameter by which to evaluate the integration of trap state densities in the ITZO film and corresponding interfaces [28]. The results further imply that the interface quality is directly related to the device properties.

Figure 3 plots the typical output curves of ITZO TFTs with various $T_{\mathrm{ITZO}}$. The $V_{\mathrm{GS}}$ was altered from 5 to $20 \mathrm{~V}$ in increments of $5 \mathrm{~V}$. All devices exhibited standard n-type field-effect transistor behavior. When the TFTs were switched on, the output properties presented enhancement-mode operation with a clear pinch-off phenomenon regardless of the $T_{\text {ITZO }}$. For the devices based on 45 and $75 \mathrm{~nm}$ $T_{\text {ITZO }}$, the current saturation response was evidently observed. The saturation current under the identical $V_{\mathrm{GS}}$ and $V_{\mathrm{DS}}$ biases gradually increased with the $T_{\text {ITZO }}$. For $100 \mathrm{~nm} T_{\text {ITZO TFT, a similar }}$ current saturation response was also obtained when the $V_{\mathrm{GS}}$ was controlled below $15 \mathrm{~V}$. However, the output characteristics expressed a current increase under high drain and source voltages of $20 \mathrm{~V}$. This phenomenon can be explained by the kink effect that impacts ionization-induced hole flow towards the source side. Moreover, electrons were injected into the channel from the source side and collected at the drain region. The extra drain current accelerated the impact ionization probability. Consequently, this effect led to a sharp rise in the output characteristics, which was in agreement with the results for the transfer characteristics.

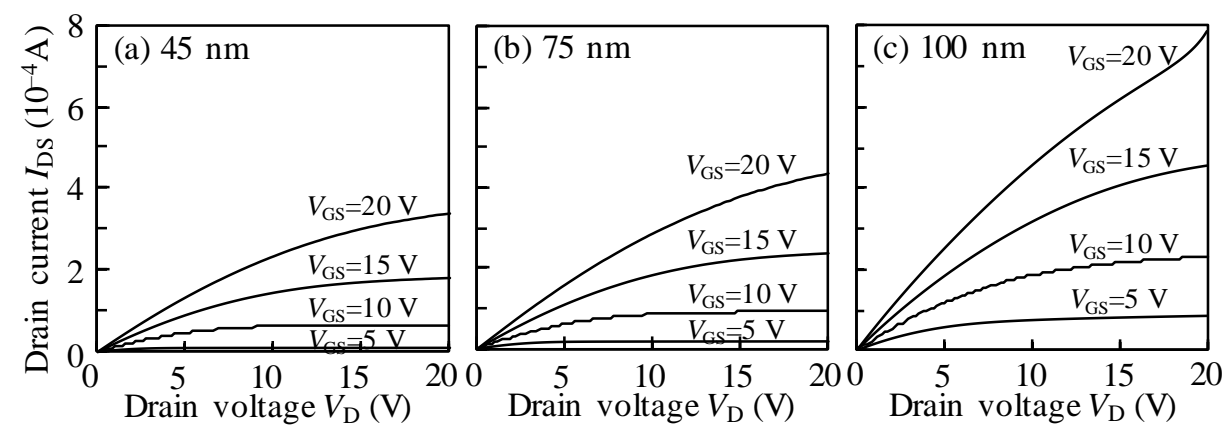

Figure 3. Output characteristics of TFT devices with various $T_{\text {ITZO }}$ of (a) 45, (b) 75, and (c) $100 \mathrm{~nm}$.

To comprehend the influence of measurement temperatures on the DCS-induced instability of ITZO TFTs with various $T_{\text {ITZO }}$, the test platform temperatures were set to $25,50,75$, and $100{ }^{\circ} \mathrm{C}$, and the DCS of $V_{\mathrm{GS}}=V_{\mathrm{DS}}=10 \mathrm{~V}$ was fixed for $10^{4} \mathrm{~s}$. To avoid the abnormal transfer curve shift occurring, a $V_{\mathrm{DS}}$ of $10.1 \mathrm{~V}$ was chosen. The variations in the transfer properties of ITZO TFTs with different $T_{\text {ITZO }}$ were studied under DCS at various test temperatures (Figure 4). Correspondingly, the changes in $V_{\mathrm{ON}}\left(\Delta V_{\mathrm{ON}}\right)$ accompanied by DCS time under various test temperatures are shown in Figure 5. It is noted that the current fluctuations in the OFF-current region are observed in some I-V curves. This phenomenon may be due to the poor shielding effect of the test platform during the measurement process. Even so, a current level of below $10^{-13}$ A had no effect on the DCS evaluation. For the devices measured at room temperature, all of the transfer curves exhibited stable behaviors even throughout a long-term duration, suggesting that a high quality GI layer has been fabricated, and the electrons were 
seldom captured at the ITZO/GI interface. As the test temperature was raised to $50{ }^{\circ} \mathrm{C}$, the electrical properties of 45 and $75 \mathrm{~nm} T_{\text {ITZO }}$ TFTs still presented a steady state. However, in terms of the device with a thick $T_{\text {ITZO }}$ of $100 \mathrm{~nm}$, a parallel shift in the transfer characteristics with a $\Delta V_{\mathrm{ON}}$ of $-1.60 \mathrm{~V}$ was observed after the DCS duration. The results indicate that a high temperature promotes thermal movement of the electron, contributing to the occurrence probability of impact ionization. As the temperature was further adjusted to $75^{\circ} \mathrm{C}$, the transfer curves of the TFT with $45 \mathrm{~nm} T_{\text {ITZO }}$ shifted by $1.02 \mathrm{~V}$ towards a positive $V_{\mathrm{GS}}$ direction with unchanged SS during the $10^{4} \mathrm{~s}$ stress time, demonstrating that the generated electrons induced by thermal activation were trapped at the front interface. It was

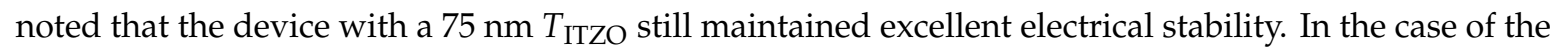
$100 \mathrm{~nm} T_{\text {ITZO }}$ device, the motion behavior was enlarged and the $\Delta V_{\mathrm{ON}}$ was aggravated to $-1.85 \mathrm{~V}$. When the platform temperature was increased to a harsh condition of $100{ }^{\circ} \mathrm{C}$, the transfer curves of

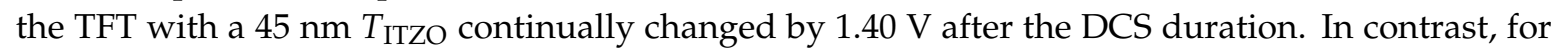
the $T_{\text {ITZO }}$ thicknesses of 75 and $100 \mathrm{~nm}$, the transfer characteristics showed parallel movement in a negative way and the $\Delta V_{\mathrm{ON}}$ values were respectively exacerbated to -1.27 and $-3.18 \mathrm{~V}$ over the whole DCS time. These results state that temperature plays a key role in exciting electron movement, thereby concretizing and enlarging electron-related effects.

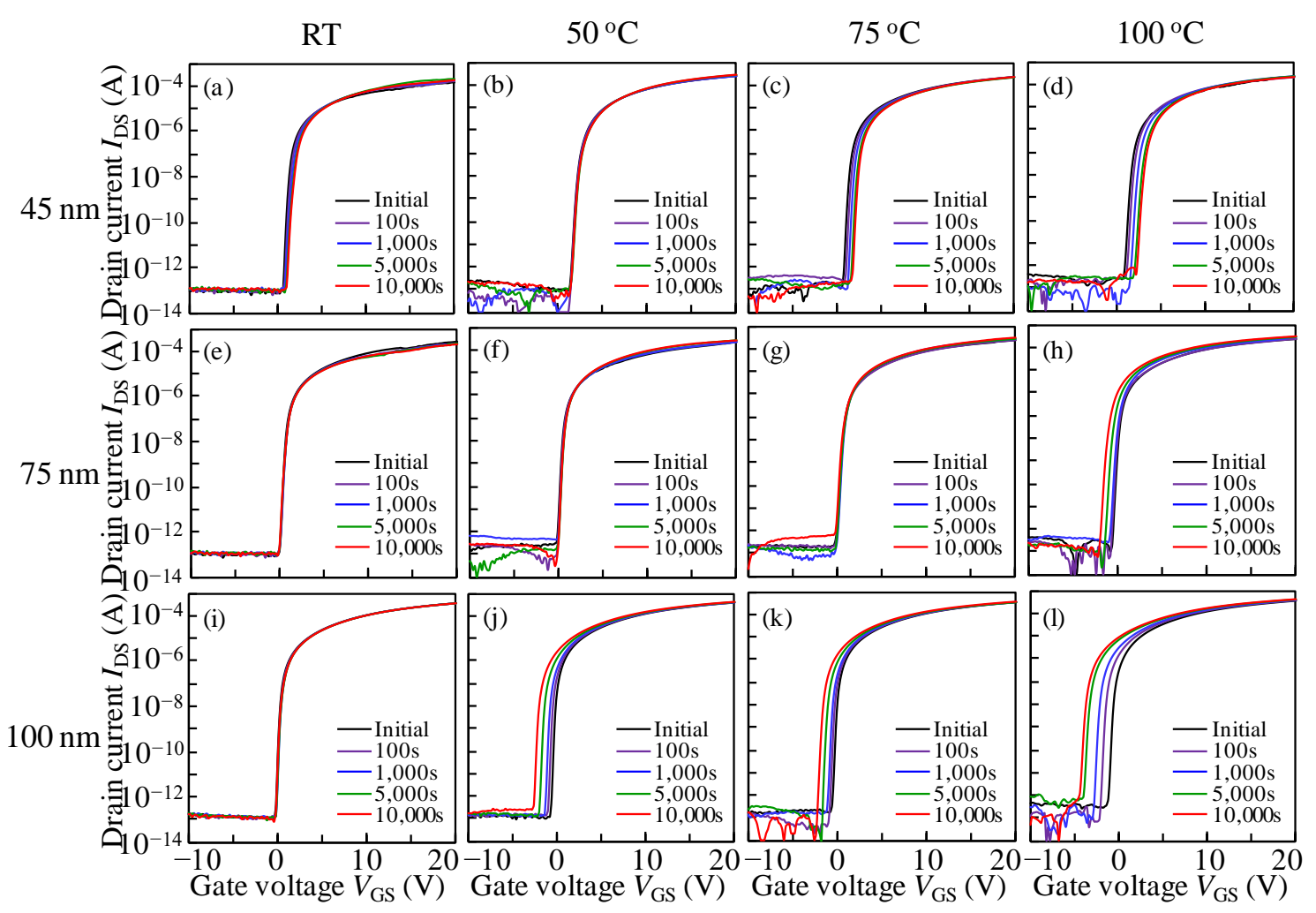

Figure 4. Evolution of transfer characteristics as a function of DCS ( $\left.V_{\mathrm{GS}}=V_{\mathrm{DS}}=10 \mathrm{~V}\right)$ duration for $10^{4} \mathrm{~s}$ for the devices with a $T_{\text {ITZO }}$ of $45 \mathrm{~nm}$ measured at test temperatures of (a) 25, (b) 50, (c) 75, and (d) $100{ }^{\circ} \mathrm{C}$; with a $T_{\text {ITZO }} 75 \mathrm{~nm}$ measured at test temperatures of (e) 25, (f) 50, (g) 75, and (h) $100{ }^{\circ} \mathrm{C}$; and with a $T_{\text {ITZO }}$ of $100 \mathrm{~nm}$ measured at test temperatures of (i) 25 , (j) 50, (k) 75 , and (l) $100{ }^{\circ} \mathrm{C}$. 


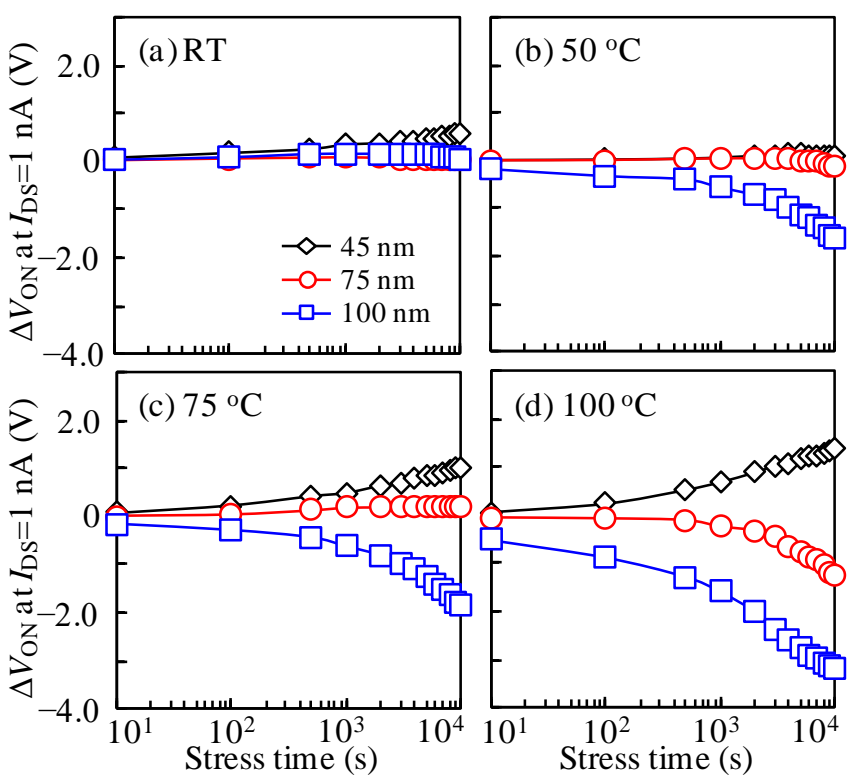

Figure 5. Variation in the $\Delta V_{\mathrm{ON}}$ with DCS duration for the TFT devices measured at test temperatures of (a) RT, (b) 50, (c) 75 , and (d) $100{ }^{\circ} \mathrm{C}$.

To further study DCS-caused instability of the ITZO TFTs with various $T_{\text {ITZO }}$, the $I_{\text {DS }}$ values of 10 , 60,120 , and $180 \mu \mathrm{A}$ adjusted by the gate and drain voltages $\left(V_{\mathrm{GS}}=V_{\mathrm{DS}}\right)$ were applied at $50{ }^{\circ} \mathrm{C}$ up to the stress duration of $10^{4} \mathrm{~s}$. It should be noted that these $I_{\mathrm{DS}}$ values are much higher than those applied in conventional active-matrix organic light-emitting diodes displays $(\sim 2 \mu \mathrm{A})$ [29]. Figure 6 displays the corresponding variation in the transfer curves of the devices. Note that the transfer characteristics of all TFTs under various $I_{\mathrm{DS}}$ stresses exhibit a parallel shift without SS degradation. The corresponding $\Delta V_{\text {ON }}$ fluctuations are plotted in Figure 7. All devices exhibit acceptable reliability under $10 \mu \mathrm{A}$ DCS irrespective of the $T_{\text {ITZO }}$, implying that few electron trapping sites exist in the ITZO bulk and at the ITZO/GI interface. Interestingly, with the increase in the $I_{\mathrm{DS}}$ stress, a $\Delta V_{\text {ON }}$ with a significant $T_{\text {ITZO }}$ dependence was observed. For the $45 \mathrm{~nm} T_{\text {ITZO }}$ TFT, the $V_{\text {ON }}$ positively shifted with the increase in the $I_{\mathrm{DS}}$ stress. The positive shift behavior was enlarged by increasing the stress duration. For the $180 \mu \mathrm{A} I_{\mathrm{DS}}$ stress, the transfer curves parallel shifted by $1.21 \mathrm{~V}$ towards the positive $V_{\mathrm{GS}}$ direction under the stress duration of $3000 \mathrm{~s}$. In the subsequent stress time, the $\Delta V_{\mathrm{ON}}$ shift was saturated in a short stress time, and then slightly moved back to $1.10 \mathrm{~V}$. In contrast, when the thickness increased to 75 and $100 \mathrm{~nm}$, the transfer curves completely changed in the negative $V_{\mathrm{GS}}$ direction irrespective of the $I_{\mathrm{DS}}$ stress. Under the $180 \mu \mathrm{A} I_{\mathrm{DS}}$ stress, the $\Delta V_{\mathrm{ON}}$ of the TFTs with $T_{\text {ITZO }}$ of 75 and $100 \mathrm{~nm}$ decreased by -2.98 and $-3.50 \mathrm{~V}$, respectively. The results demonstrate that, under identical $I_{\mathrm{DS}}$ stress, the negative $V_{\mathrm{ON}}$ shift is accelerated with the increase in $T_{\text {ITZO }}$.

Generally, the positive $V_{\mathrm{ON}}$ shift was due to electron trapping at the front-channel interface, while the $V_{\mathrm{ON}}$ shift to the negative $V_{\mathrm{GS}}$ direction was due to hole trapping at the active layer/etch-stopper interface under the $I_{\mathrm{DS}}$ stress. For the $45 \mathrm{~nm} T_{\mathrm{ITZO}}$ device under low $I_{\mathrm{DS}}(<180 \mu \mathrm{A})$ stress $\left(V_{\mathrm{DS}}=V_{\mathrm{GS}}\right)$, electrons drifted to the gate insulator/ITZO region. Simultaneously, electron trapping occurred immediately at the gate insulator/ITZO interface, as illustrated in the corresponding schematic diagram (Figure 8a). 


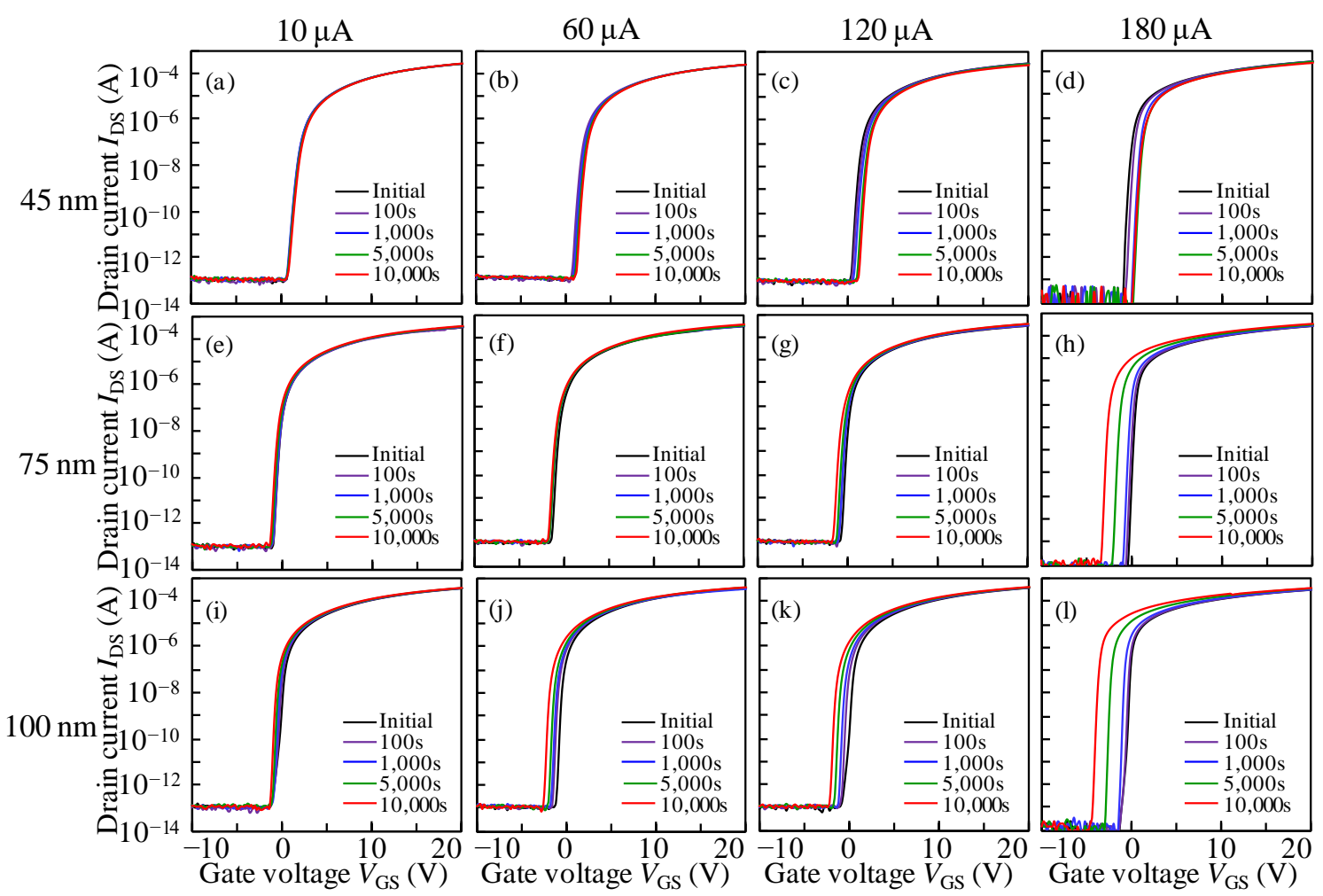

Figure 6. Evolution of transfer characteristics as a function of $10^{4} \mathrm{~s}$ DCS duration with the test temperature of $50{ }^{\circ} \mathrm{C}$ for the devices with a $T_{\text {ITZO }}$ of $45 \mathrm{~nm}$ under $I_{\mathrm{DS}}$ stresses of (a) 10, (b) 60, (c) 120,

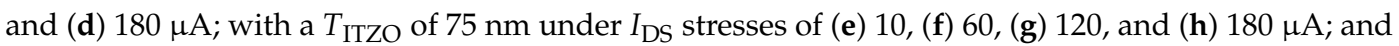
with a $T_{\text {ITZO }}$ of $100 \mathrm{~nm}$ under $I_{\mathrm{DS}}$ stresses of (i) 10, (j) 60, (k) 120, and (1) $180 \mu \mathrm{A}$.

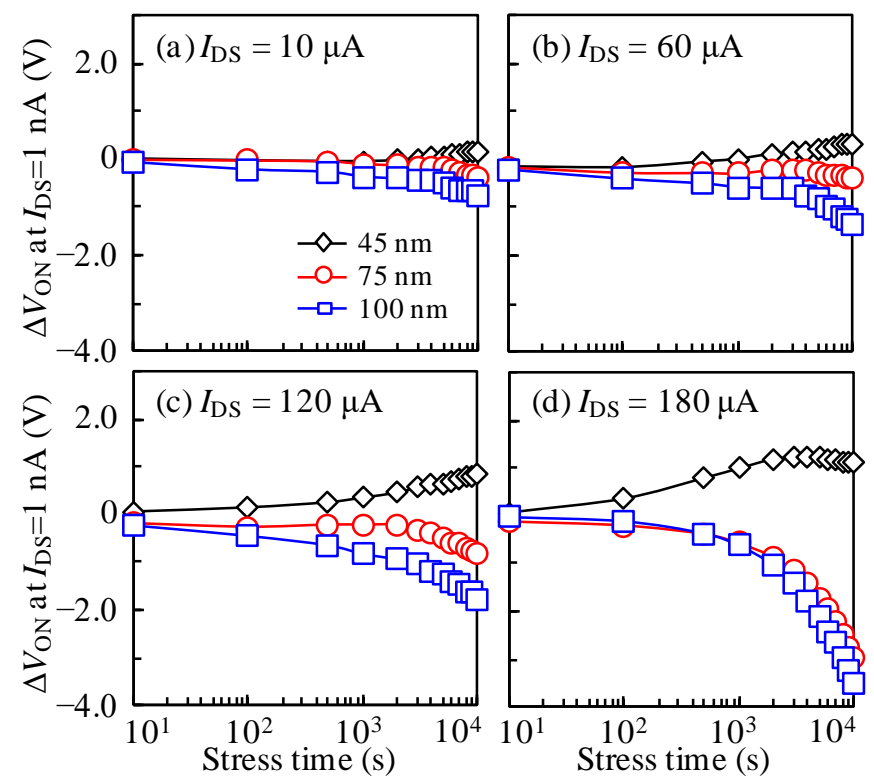

Figure 7. Variation in the $\Delta V_{\mathrm{ON}}$ with DCS duration for the TFT devices measured at $I_{\mathrm{DS}}$ stresses of (a) 10, (b) 60, (c) 120, and (d) $180 \mu \mathrm{A}$. 
(a)

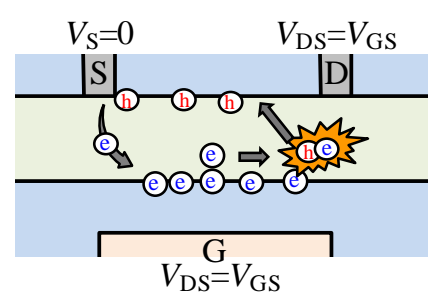

(b)

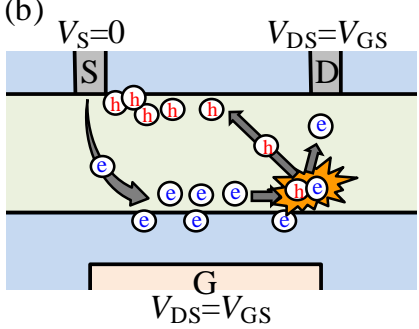

Figure 8. The schematic diagram of impact ionization mechanism of DCS-originated instability in the devices with a $T_{\text {ITZO }}$ of (a) 45 and (b) 75 and $100 \mathrm{~nm}$.

As the $I_{\mathrm{DS}}$ stress increases, the electron trapping probability is enhanced. When the $I_{\mathrm{DS}}$ increases to $180 \mu \mathrm{A}$, electron trapping is the main origin of the positive $V_{\mathrm{ON}}$ shift within the stress duration of $1000 \mathrm{~s}$. Consequently, a saturated trapping behavior is then observed. When the stress time exceeds $3000 \mathrm{~s}$, hole trapping seems to become a major reason for the slightly negative $V_{\text {ON }}$ shift. It can be explained by the impact ionization phenomenon [21], which induces the generation of an electron-hole pair. Consequently, the excited charges are trapped at the front- and back-channel interfaces. However, the electron trapping seems to become saturated at the gate insulator/ITZO region. Therefore, the extra electrons are drained from the drain electrode. The holes generated near the drain side migrate to the source region along the back-channel interface and accumulate near the source region. As a result, the $V_{\mathrm{ON}}$ shifts from a positive to negative $V_{\mathrm{GS}}$ direction. When the $T_{\mathrm{ITZO}}$ increases to $75 \mathrm{~nm}$ and more, a clear negative $V_{\mathrm{ON}}$ shift is observed under various $I_{\mathrm{DS}}$ stresses, demonstrating that hole trapping at the ITZO/etch-stopper interface is the main cause of the negative $V_{\text {ON }}$ shift. With the increase in the $T_{\text {ITZO }}$, the negative $V_{\text {ON }}$ shift is accelerated under the identical $I_{\mathrm{DS}}$ stress. The results demonstrate that, for the thicker $T_{\text {ITZO }}$ TFTs, electrons injected from the source will experience a longer duration prior to reaching the gate insulator/ITZO interface under the vertical electric field. Simultaneously, electrons are subjected to a driving force from the lateral electric field. It is noted that the identical $I_{\mathrm{DS}}$ bias is controlled with different $V_{\mathrm{GS}}=V_{\mathrm{DS}}$ values for various $T_{\mathrm{ITZO}}$ TFTs. Therefore, the probability of electron-induced impact ionization is greatly increased with sufficient space and time, contributing to more excited carriers (Figure $8 \mathrm{~b}$ ). It is noted that the forward and reverse transfer curves were compared after DCS, and the similar transfer curves were obtained without SS degradation. Therefore, the results suggest that the observed phenomenon is hard to attribute to the increase in the donor-like states near the source side of the TFTs.

On the basis of the above-mentioned discussions, the obtained results suggest that, in the high- $\mu$ devices, the DCS-induced impact ionization is dependent on the generation of electron-hole pairs, which is closely proportional to the channel layer thickness, test temperature, applied electric field, and drain current density. In other words, the structural design of the devices and the control of test conditions should be well considered to promote the stability performance of the devices.

\section{Conclusions}

In summary, the ITZO TFTs with various $T_{\text {ITZO }}$ were fabricated and the DCS-induced instabilities under different test temperatures and $I_{\mathrm{DS}}$ values were investigated. All the TFT devices possessed excellent electrical properties irrespective of the $T_{\text {ITZO }}$, including a high $\mu_{\text {sat }}$ of $>35 \mathrm{~cm}^{2} \mathrm{~V}^{-1} \mathrm{~s}^{-1}$ and

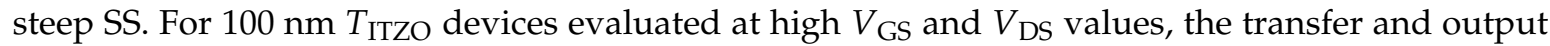
characteristics exhibited an abnormal rise in current. This phenomenon can be ascribed to the floating body effect that impacts ionization occurring near the drain region. More importantly, with the variation in the $T_{\text {ITZO }}$, the synergistic effects of temperature and $I_{\text {DS }}$ value on DCS-induced instability were well understood. The results further demonstrate that the abnormal negative shift behavior in TFT devices with the $T_{\text {ITZO }}$ of greater than $75 \mathrm{~nm}$ is gradually enlarged with the increase in temperature and $I_{\mathrm{DS}}$ values. This study provides a method with which to comprehend the DCS-originating degradations for high-performance ITZO-based TFT devices. 
Author Contributions: Conceptualization, M.F. and D.W.; Methodology, D.W., S.T., and K.Y.; Validation, M.F. and D.W.; Formal Analysis, D.W.; Writing-Original Draft Preparation, D.W.; Writing-Review \& Editing, M.F. and D.W. All authors have read and agreed to the published version of the manuscript.

Funding: This research was funded by the National Key Research and Development Program of China (2016YFA0202403), the National Nature Science Foundation of China (61674098, 91733301), the Fundamental Research Funds for the Central Universities (GK201903052), the Changjiang Scholar and the Innovative Research Team (IRT_14R33), the 111 Project (B14041), and the Chinese National 1000-talent-plan program (Grant No. 111001034). This work was partly supported by JSPS KAKENHI Grant Number 16K06309.

Acknowledgments: The authors would like to thank Idemitsu Kosan Co. Ltd., for their support throughout this work.

Conflicts of Interest: The authors declare no conflict of interest.

\section{References}

1. Nomura, K.; Ohta, H.; Takagi, A.; Kamiya, T.; Hirano, M.; Hosono, H. Room-temperature fabrication of transparent flexible thin-film transistors using amorphous oxide semiconductors. Nature 2004, 432, 488-492. [CrossRef] [PubMed]

2. Hirao, T.; Furuta, M.; Hiramatsu, T.; Matsuda, T.; Li, C.; Furuta, H.; Hokari, H.; Yoshida, M.; Ishii, H.; Kakegawa, M. Bottom-gate zinc oxide thin-film transistors (ZnO TFTs) for AM-LCDs. IEEE Trans. Electron Devices 2008, 55, 3136-3142. [CrossRef]

3. Shin, K.Y.; Tak, Y.J.; Kim, W.-G.; Hong, S.; Kim, H.J. Improvement of Electrical Characteristics and Stability of Amorphous Indium Gallium Zinc Oxide Thin Film Transistors Using Nitrocellulose Passivation Layer. ACS Appl. Mater. Interfaces 2019, 9, 13278-13285. [CrossRef] [PubMed]

4. Lee, Y.L.; Lee, C.H.; Nam, T.; Lee, S.; Oh, I.-K.; Yang, J.Y.; Choi, D.W.; Yoo, C.; Kim, H.-J.; Kim, W.-H.; et al. Hydrogen barrier performance of sputtered $\mathrm{La}_{2} \mathrm{O}_{3}$ films for InGaZnO thin-film transistor. J. Mater. Sci. 2019, 54, 11145-11156. [CrossRef]

5. Wang, C.-J.; You, H.-C.; Ou, J.-H.; Chu, Y.-Y.; Ko, F.-H. Ultraviolet Photodetecting and Plasmon-to-Electric Conversion of Controlled Inkjet-Printing Thin-Film Transistors. Nanomaterials 2020, 10, 458. [CrossRef]

6. Barros, R.; Saji, K.J.; Waerenborgh, J.C.; Barquinha, P.; Pereira, L.; Carlos, E.; Martins, R.; Fortunato, E. Role of Structure and Composition on the Performances of P-Type Tin Oxide Thin-Film Transistors Processed at Low-Temperatures. Nanomaterials 2019, 9, 320. [CrossRef]

7. Zan, H.-W.; Yeh, C.-C.; Meng, H.-F.; Tsai, C.-C.; Chen, L.H. Achieving High Field-Effect Mobility in Amorphous Indium-Gallium-Zinc Oxide by Capping a Strong Reduction Layer. Adv. Mater. 2012, 24, 3509-3514. [CrossRef]

8. Wang, C.-J.; You, H.-C.; Lin, K.; Ou, J.-H.; Chao, K.-H.; Ko, F.-H. Highly Transparent and Surface-Plasmon-Enhanced Visible-Photodetector Based on Zinc Oxide Thin-Film Transistors with Heterojunction Structure. Materials 2019, 12, 3639. [CrossRef]

9. Zhou, C.; Ai, Q.; Chen, X.; Gao, X.; Liu, K.; Shen, D. Ultraviolet photodetectors based on wide bandgap oxide semiconductor films. Chin. Phys. B 2019, 28, 048503. [CrossRef]

10. Zhao, W.; Li, H.; Li, D.; Liu, Z.; Wang, D.; Liu, S. Comprehensive investigation of sputtered and spin-coated zinc oxide electron transport layers for highly efficient and stable planar perovskite solar cells. J. Power Sources 2019, 427, 223-230. [CrossRef]

11. Li, H.; Li, D.; Zhao, W.; Yuan, S.; Liu, Z.; Wang, D.; Liu, S. NaCl-Assisted Defect Passivation in the Bulk and Surface of $\mathrm{TiO}_{2}$ Enhancing Efficiency and Stability of Planar Perovskite Solar Cells. J. Power Sources 2020, 448, 227586. [CrossRef]

12. Wang, D.; Li, C.; Furuta, M. Influence of Active Layer Thickness on Performance and Reliability of InSnZnO Thin-film Transistors. In Proceedings of the 19th International Workshop on AM-FPD, Kyoto, Japan, 4-6 July 2012; pp. 159-162.

13. Nakata, M.; Zhao, C.; Kanicki, J. DC sputtered amorphous In-Sn-Zn-O thin-film transistors: Electrical properties and stability. Solid State Electron. 2016, 116, 22-29. [CrossRef]

14. Park, H.-W.; Park, K.; Kwon, J.-Y.; Choi, D.; Chung, K.-B. Effect of active layer thickness on device performance of tungsten-doped InZnO thin-film transistor. IEEE Trans. Electron Devices 2016, 64, 159-163. [CrossRef] 
15. Park, J.; Kim, Y.S.; Kim, J.H.; Park, K.; Park, Y.C.; Kim, H.-S. The effects of active layer thickness and annealing conditions on the electrical performance of ZnON thin-film transistors. J. Alloy. Compd. 2016, 688, 666-671. [CrossRef]

16. Yang, Z.; Yang, J.; Meng, T.; Qu, M.; Zhang, Q. Influence of channel layer thickness on the stability of amorphous indium zinc oxide thin film transistors. Mater. Lett. 2016, 166, 46-50. [CrossRef]

17. Wang, D.; Hung, M.P.; Jiang, J.; Toda, T.; Furuta, M. Suppression of degradation induced by negative gate bias and illumination stress in amorphous InGaZnO thin-film transistors by applying negative drain bias. ACS Appl. Mater. Interfaces 2014, 6, 5713-5718. [CrossRef]

18. Zhang, J.; Yang, J.; Li, Y.; Wilson, J.; Ma, X.; Xin, Q.; Song, A. High performance complementary circuits based on p-SnO and n-IGZO thin-film transistors. Materials 2017, 10, 319. [CrossRef]

19. Lee, S.; Chen, Y.; Kim, J.; Kim, H.-M.; Jang, J. Transparent AMOLED display driven by split oxide TFT backplane. J. Soc. Inf. Disp. 2018, 26, 164-168. [CrossRef]

20. Chen, Y.; Geng, D.; Jang, J. Integrated Active-Matrix Capacitive Sensor Using a-IGZO TFTs for AMOLED. IEEE J. Electron Devices Soc. 2018, 6, 214-218. [CrossRef]

21. Wang, D.; Zhao, W.; Li, H.; Furuta, M. Drain Current Stress-Induced Instability in Amorphous InGaZnO Thin-Film Transistors with Different Active Layer Thicknesses. Materials 2018, 11, 559. [CrossRef]

22. Yue, L.; Pu, H.-F.; Li, H.-L.; Pang, S.-J.; Zhang, Q. Effect of active layer thickness on device performance of a-LZTO thin-film transistors. Superlattice Microstruct. 2013, 57, 123-128. [CrossRef]

23. Lee, S.; Jeon, S.; Nathan, A. Modeling Sub-Threshold Current-Voltage Characteristics in Thin Film Transistors. J. Disp. Technol. 2013, 9, 883-889.

24. Kamiya, T.; Hosono, H. Material characteristics and applications of transparent amorphous oxide semiconductors. NPG Asia Mater. 2010, 2, 15-22. [CrossRef]

25. Choi, H.-S.; Jeon, S.; Kim, H.; Shin, J.; Kim, C.; Chung, U.I. The impact of active layer thickness on low-frequency noise characteristics in InZnO thin-film transistors with high mobility. Appl. Phys. Lett. 2012, 100, 173501. [CrossRef]

26. Valdinoci, M.; Colalongo, L.; Baccarani, G.; Fortunato, G.; Pecora, A.; Policicchio, I. Floating body effects in polysilicon thin-film transistors. IEEE Trans. Electron Devices 1997, 44, 2234-2241. [CrossRef]

27. Jiang, J.; Wang, D.; Matsuda, T.; Kimura, M.; Liu, S.; Furuta, M. Influence of Interface Traps on the Electrical Properties of Oxide Thin-Film Transistors with Different Channel Thicknesses. J. Nano Res. 2017, 46, 93-99. [CrossRef]

28. Li, Y.; Pei, Y.L.; Hu, R.Q.; Chen, Z.M.; Zhao, Y.; Shen, Z.; Fan, B.F.; Liang, J.; Wang, G. Effect of channel thickness on electrical performance of amorphous IGZO thin-film transistor with atomic layer deposited alumina oxide dielectric. Curr. Appl. Phys. 2014, 14, 941-945. [CrossRef]

29. Lee, H.; Lin, Y.-C.; Shieh, H.P.D.; Kanicki, J. Current-scaling a-Si:H TFT pixel-electrode circuit for AM-OLEDs: Electrical properties and stability. IEEE Trans. Electron Devices 2007, 54, 2403-2410. 